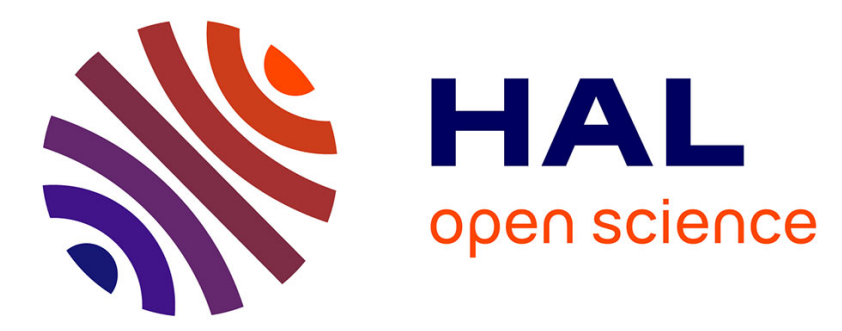

\title{
Synthesis and characterization of diblock and statistical copolymers based on hydrolyzable siloxy silylester methacrylate monomers
}

\author{
Marlene Lejars, André Margaillan, Christine Bressy
}

\section{To cite this version:}

Marlene Lejars, André Margaillan, Christine Bressy. Synthesis and characterization of diblock and statistical copolymers based on hydrolyzable siloxy silylester methacrylate monomers. Polymer Chemistry, 2014, 5 (6), pp.2109 - 2117. hal-00972026

HAL Id: hal-00972026

https://hal-univ-tln.archives-ouvertes.fr/hal-00972026

Submitted on 3 Apr 2014

HAL is a multi-disciplinary open access archive for the deposit and dissemination of scientific research documents, whether they are published or not. The documents may come from teaching and research institutions in France or abroad, or from public or private research centers.
L'archive ouverte pluridisciplinaire HAL, est destinée au dépôt et à la diffusion de documents scientifiques de niveau recherche, publiés ou non, émanant des établissements d'enseignement et de recherche français ou étrangers, des laboratoires publics ou privés. 


\title{
Synthesis and characterization of diblock and statistical copolymers based on hydrolyzable siloxy silylester methacrylate monomers $\uparrow$
}

\begin{abstract}
Marlène Lejars, * André Margaillan and Christine Bressy
Statistical and diblock copolymers of bis(trimethylsiloxy)methylsilyl methacrylate (MATM2), a hydrolyzable monomer containing a silylester and a siloxane group, and methyl methacrylate (MMA) were synthesized by the RAFT process. The controlled character of the MATM2 RAFT polymerization using 2-cyanoprop2-yl-dithiobenzoate (CPDB) or S-(2-cyanoprop-2-yl)-S-dodecyltrithiocarbonate as chain transfer agents was assessed by linear pseudo-first-order kinetics, linear molar mass growth with monomer conversion and low molar-mass dispersity. The hydrolysis kinetics of pMATM2 homopolymers was investigated by in situ ${ }^{1} \mathrm{H}$-NMR and compared to several methacrylic homopolymers bearing hydrolyzable tri-alkylsilylester side groups. PMATM2-block-pMMA diblock copolymers were synthesized by in situ chain extension with methyl methacrylate, using pMATM2-CPDB as a macro-CTA. p(MATM2-stat-MMA) statistical copolymers were synthesized by simultaneous polymerization of MATM2 and MMA by the RAFT process. The monomer reactivity ratios for MATM2 $\left(r_{1}=1.29\right)$ and MMA $\left(r_{2}=0.62\right)$ were obtained from the Mayo Lewis equation using the least-squares method. All the copolymers synthesized by the RAFT process had molar masses close to the targeted values and low dispersities $\left(\Theta_{M}<1.15\right)$. DSC analysis and contact angle measurements revealed the influence of the copolymer microstructure (statistical or diblock) on their glass transition temperature and surface energy.
\end{abstract}

Received 15th November 2013 Accepted 4th December 2013

DOI: 10.1039/c3py01603j

www.rsc.org/polymers tert-butyldimethylsilyl methacrylate (TBDMSiMA) and methyl methacrylate (MMA) with a diblock microstructure compared to statistical copolymers. ${ }^{2,3}$

Fouling Release Coatings (FRCs) represent a second type of antifouling coatings whose efficiency relies on the hydrophobicity and low surface energy of their poly(dimethylsiloxane) (PDMS) cross-linked matrix, without the use of biocides. ${ }^{4}$ These coatings limit the adhesion strength of marine organisms on their surface, so fouling can be easily removed by hydrodynamic forces when the boat is sailing.

The synthesis of new polymers which are both hydrolyzable and hydrophobic/low-surface energy materials is now being attractive for the development of environmentally friendly FRC-SPC hybrid antifouling coatings. In this way, graft copolymers based on TBDMSiMA and a hydrophobic/low surface energy PDMS methacrylate monomer have already been synthesized. ${ }^{5}$

In this paper we report, for the first time, the controlled polymerization of bis(trimethylsiloxy)methylsilyl methacrylate (MATM2), an original monomer combining both a hydrolyzable silylester structure, characteristic of SPC binders, and a siloxane moiety, characteristic of FRCs. The RAFT polymerization has been chosen among the reversible deactivation radical polymerization (RDRP) techniques due to its applicability to a wide range of monomers and tolerance of a wide variety of functional groups under mild conditions..$^{6-8}$ Block copolymers with narrow
Université de Toulon, Laboratoire MAPIEM, EA 4323, 83957 La Garde, France. E-mail: marlene.lejars@univ-tln.fr; Fax: +334941424 48; Tel: +33494142272

$\uparrow$ Electronic supplementary information (ESI) available. See DOI: 10.1039/c3py01603j 
molar mass distributions can be easily synthesized, without any impurities or residual reagents.

The homopolymerization of MATM2 was first studied, in conventional radical polymerization and RAFT polymerization, using 2-cyanoprop-2-yl dithiobenzoate (CPDB) or $S$-(2-cyanoprop-2-yl)-S-dodecyltrithiocarbonate (CTA-0610) as chain transfer agents (CTAs). Diblock and statistical copolymers were prepared by sequential or simultaneous polymerization of MATM2 with MMA using the RAFT process. The hydrolysis kinetics of pMATM2 homopolymers was investigated by in situ ${ }^{1} \mathrm{H}-\mathrm{NMR}$ and compared to other hydrolyzable tri-alkylsilylesterbased methacrylic homopolymers. DSC analysis and contact angle measurements were carried out to investigate the influence of the copolymer microstructure (statistical or diblock) on their glass transition temperature and surface energy.

\section{Experimental section}

\section{Materials}

Bis(trimethylsiloxy)methylsilyl methacrylate (MATM2) was kindly supplied by Momentive (Germany), distilled under reduced pressure and stored under argon before use. 2-Cyanoprop-2-yl dithiobenzoate (CPDB) and $S$-(2-cyanoprop-2-yl)- $S$ dodecyltrithiocarbonate (CTA-0610) were purchased from Strem Chemicals and used without further purification. 2,2'-Azobisisobutyronitrile (AIBN) was purchased from Aldrich and purified by recrystallization from methanol. Xylene was purchased from Acros and distilled under reduced pressure with $\mathrm{CaH}_{2}$ before use. Methanol was purchased from Acros and used without further purification.

\section{Analytical techniques}

NMR spectroscopy. ${ }^{1} \mathrm{H}-\mathrm{NMR}$ measurements were carried out on a Brüker Advance 400 (400 MHz) spectrometer with deuterated chloroform $\left(\mathrm{CDCl}_{3}\right)$ as a solvent at room temperature.

The hydrolysis kinetic studies were carried out in NMR tubes, adding $10 \mu \mathrm{L}$ of a pH 10 buffer into $1 \mathrm{~mL}$ of a homopolymer solution $\left(15 \mathrm{mg} \mathrm{mL}^{-1}\right.$ in THF- $\left.\mathrm{d}_{8}\right) .{ }^{1} \mathrm{H}-\mathrm{NMR}$ spectra were recorded at different time intervals to monitor the evolution of the proportion of the hydrolyzed and non-hydrolyzed monomer units in the polymer.

Molar mass characterization. The number-average molar mass $\left(M_{\mathrm{n}}\right)$ and molar-mass dispersity $\left(\bigoplus_{\mathrm{M}}\right)$ of the polymers were determined by Triple Detection Size Exclusion Chromatography (TD-SEC). Analyses were performed on a Viscotek apparatus composed of a GPC Max (comprising a degazer, a pump and an autosampler) with a TDA-302 (RI detector, right and low angle light scattering detector at $670 \mathrm{~nm}$ and viscometer), and a UV detector. The following Viscotek columns were used: a HHR-H precolumn, GMHHR-H and GMHHR-L ViscoGel columns. THF was used as the eluent with a flow rate of $1.0 \mathrm{~mL} \mathrm{~min}^{-1}$ at $30{ }^{\circ} \mathrm{C}$. Purified polymers were dissolved in THF at ca. $10 \mathrm{mg} \mathrm{mL}^{-1}$ and filtered on a $0.2 \mu \mathrm{m}$ PTFE filter. Molar masses were calculated using the value of the refractive index increment $\mathrm{d} n / \mathrm{d} c$ calculated for each purified polymer using the OmniSec software. For nonpurified polymers, the molar masses were determined by TD-SEC using an estimated value of their $\mathrm{d} n / \mathrm{d} c$ (see ESI $\dagger$ ). The theoretical molar mass $M_{\mathrm{n}}^{\text {th }}$ was obtained using eqn (1) where $M_{\text {monomer }}$ and $M_{\mathrm{CTA}}$ are the molar masses of the monomer and the RAFT agent, respectively, and conv. refers to the monomer conversion.

$$
M_{\mathrm{n}}^{\text {th }}=\frac{[\text { monomer }]}{[\mathrm{CTA}]} \times M_{\text {monomer }} \times \text { conv. }+M_{\mathrm{CTA}}
$$

Differential scanning calorimetry (DSC). The glass transition temperatures $\left(T_{\mathrm{g}}\right)$ of the polymers were measured with a Q100 differential scanning calorimeter (TA Instruments). After an annealing step at $150{ }^{\circ} \mathrm{C}$, the samples were cooled down to -50 ${ }^{\circ} \mathrm{C}$ at the maximum cooling rate of the instrument and then scanned at a heating rate of $20{ }^{\circ} \mathrm{C} \mathrm{min}{ }^{-1}$ from -50 to $150{ }^{\circ} \mathrm{C}$. The $T_{\mathrm{g}}$ values were determined as the midpoint between the onset and the end of a step transition using the TA Instruments Universal Analysis 2000 software.

Contact angle and surface energy measurements. Each purified polymer was solubilized in xylene, at a 40-50 wt\% solid content, and applied on abraded poly(vinyl chloride) (PVC) substrates (ca. $25 \mathrm{~mm} \times 50 \mathrm{~mm}$ ) with a bar-coater resulting in $100 \mu \mathrm{m}$ dried thickness coatings. For polymers which cannot be purified, the reaction mixture was directly applied on PVC substrates. Solvent evaporation occurred at room temperature.

The contact angles and surface energies were obtained using a DIGIDROP apparatus (GBX Instrument) equipped with a syringe and a flat-tipped needle. $1 \mu \mathrm{L}$ droplets of deionized water $\left(\gamma_{\mathrm{L}}=\right.$ $72.8 \mathrm{~mJ} \mathrm{~m}^{-2}, \gamma_{\mathrm{L}}^{\mathrm{d}}=21.8 \mathrm{~mJ} \mathrm{~m}^{-2}$, and $\gamma_{\mathrm{L}}^{\mathrm{p}}=51.0 \mathrm{~mJ} \mathrm{~m}^{-2}$ ), glycerol $\left(\gamma_{\mathrm{L}}=64.0 \mathrm{~mJ} \mathrm{~m}^{-2}, \gamma_{\mathrm{L}}^{\mathrm{d}}=34.0 \mathrm{~mJ} \mathrm{~m}^{-2}\right.$, and $\left.\gamma_{\mathrm{L}}^{\mathrm{P}}=30.0 \mathrm{~mJ} \mathrm{~m}^{-2}\right)$ and diiodomethane $\left(\gamma_{\mathrm{L}}=50.8 \mathrm{~mJ} \mathrm{~m}^{-2}, \gamma_{\mathrm{L}}^{\mathrm{d}}=48.5 \mathrm{~mJ} \mathrm{~m}^{-2}\right.$, and $\gamma_{\mathrm{L}}^{\mathrm{p}}=$ $2.3 \mathrm{~mJ} \mathrm{~m}^{-2}$ ) were deposed on the coated panels. The reported contact angles were an average of five individual measurements on different regions of the same coating. The surface energies were calculated by the Owens-Wendt method, ${ }^{9}$ considering the surface energy of the coating $\gamma_{S}$ as the sum of a dispersive component $\gamma_{\mathrm{S}}^{\mathrm{d}}$ and a polar component $\gamma_{\mathrm{S}}^{\mathrm{p}}$ (eqn (2)).

$$
\gamma_{\mathrm{S}}=\gamma_{\mathrm{S}}^{\mathrm{d}}+\gamma_{\mathrm{S}}^{\mathrm{p}}
$$

\section{Polymer synthesis}

Homopolymerization of MATM2. The RAFT homopolymerization of MATM2 was performed in xylene at $1.5 \mathrm{~mol} \mathrm{~L}^{-1}$, using AIBN as an initiator, and CPDB or CTA-0610 as a chain transfer agent (CTA) with a molar ratio [CTA]/[AIBN] of 5/1. The targeted molar mass $\left(M_{\mathrm{n}}^{\mathrm{tg}}\right)$ was $10000 \mathrm{~g} \mathrm{~mol}^{-1}$. In a typical experiment, a $30 \mathrm{~mL}$ solution of MATM2 (13.8 g, $45 \mathrm{mmol}$ ), CPDB (311.7 mg, $1.4 \mathrm{mmol}$ ) and AIBN (46.2 mg, $0.3 \mathrm{mmol}$ ) in xylene was prepared in a $100 \mathrm{~mL}$ round bottom flask equipped with a magnetic stir bar and argon supply. The reaction mixture was degassed through bubbling with argon, sealed, and then placed for $24 \mathrm{~h}$ in an oil bath previously heated at $70{ }^{\circ} \mathrm{C}$. Periodically, $100 \mu \mathrm{L}$ aliquots of the reaction mixture were removed from the flask for kinetics and molar mass analysis. Then, the polymer was precipitated into methanol, filtered, and dried under vacuum for $48 \mathrm{~h}$ at room temperature. 
Conventional radical homopolymerization of MATM2 was also carried out using the same experimental conditions but without the addition of CTA.

The MATM2 conversion was determined by ${ }^{1} \mathrm{H}-\mathrm{NMR}$ analysis using eqn (3) where $I_{\mathrm{a}}$ is the integration intensity of resonances of vinylic protons at $5.6 \mathrm{ppm}$ and $I_{\mathrm{c}}$ is the integration area of resonances of the three methyl protons $-\mathrm{O}_{3}-\mathrm{Si}-\mathrm{CH}_{3}$ from both the polymer and the monomer at $0.3 \mathrm{ppm}$ (Fig. S1†).

$$
\text { Conv. }=1-\frac{I_{\mathrm{a}}}{I_{\mathrm{c}} / 3}
$$

Synthesis of pMATM2-block-pMMA diblock copolymers. pMATM2-block-pMMA copolymers, with $M_{\mathrm{n}}^{\mathrm{tg}}=20000 \mathrm{~g} \mathrm{~mol}^{-1}$, were synthesized by in situ chain extension, through the polymerization of MMA using PMATM2-CPDB as a macro-CTA. The diblock copolymers with a MATM2 content ranging from 10 to $50 \mathrm{~mol} \%$ are designated as copolymers $\mathrm{b} X X$, where $\mathrm{b}$ means block and $X X$ is the MATM2 molar content (Table 1). As an example, run b20 in Table 1 was performed by adding MATM2 (11.5 g, $38 \mathrm{mmol}$ ), CPDB (296 mg, $1.3 \mathrm{mmol}$ ) and AIBN (44 mg, $0.3 \mathrm{mmol}$ ) in distilled xylene into a $250 \mathrm{~mL}$ round bottom flask equipped with a magnetic stir bar. The reaction mixture was degassed through bubbling with argon, sealed, and then placed for $24 \mathrm{~h}$, in an oil bath previously heated at $70{ }^{\circ} \mathrm{C}$. When the polymerization was achieved, a solution of MMA (15.0 g, $150 \mathrm{mmol}$ ) and AIBN (44 mg, $0.3 \mathrm{mmol}$ ) in distilled xylene previously degassed was added to the reaction mixture. The concentrations were determined so that the solid content at the end of the polymerization was $40 \mathrm{wt} \%$. The polymerization was conducted until no evolution of the monomer conversion. The polymers were precipitated into methanol, filtered and dried under vacuum for $48 \mathrm{~h}$ at room temperature.

Synthesis of p(MATM2-stat-MMA) statistical copolymers. The statistical copolymerization of MATM2 and MMA was carried out using a similar procedure to that used for the homopolymerization of MATM2. The statistical copolymers with a MATM2 content ranging from 10 to $50 \mathrm{~mol} \%$ are designated as copolymers $\mathrm{s} X X$, where s means statistical and $X X$ is the MATM2 molar content (Table 2). As an example, run s20 in Table 2 was performed by mixing MATM2 (10.7 g, $35 \mathrm{mmol})$, MMA (14.0 g, $140 \mathrm{mmol}$ ), CPDB (276 mg, $1.2 \mathrm{mmol}$ ), AIBN (41 $\mathrm{mg}, 0.3 \mathrm{mmol}$ ) and distilled xylene into a $250 \mathrm{~mL}$ round bottom flask equipped with a magnetic stir bar. The monomer concentrations were determined so that the solid content at the end of the polymerization was $40 \mathrm{wt} \%$. The reaction mixture was degassed through bubbling with argon, sealed, and then placed in an oil bath previously heated at $70{ }^{\circ} \mathrm{C}$. The polymerization was conducted until no evolution of the monomer conversion. The polymers were precipitated into pentane or a mixture of methanol-pentane, filtered and dried under vacuum for $48 \mathrm{~h}$ at room temperature.

Determination of the reactivity ratios. Xylene solutions of MATM2 (1.50 mol L ${ }^{-1}$ ), MMA (1.50 mol L $\left.{ }^{-1}\right)$, CPDB (1.05 $\mathrm{mol} \mathrm{L}^{-1}$ ) and AIBN (60 $\left.\mathrm{mmol} \mathrm{L}^{-1}\right)$ were first prepared and added to the reaction mixtures to obtain concentrations of total monomers, CDPB and AIBN equal to $1.5 \mathrm{~mol} \mathrm{~L}^{-1}, 12 \mathrm{mmol} \mathrm{L}^{-1}$

Table 1 CPDB-mediated RAFT synthesis of pMATM2-block-pMMA diblock copolymers

\begin{tabular}{|c|c|c|c|c|c|c|c|c|c|c|c|}
\hline & \multicolumn{4}{|c|}{ pMATM2 macro-CTA } & \multicolumn{7}{|c|}{ pMATM2-block-pMMA diblock copolymer } \\
\hline & $\begin{array}{l}M_{\mathrm{n}, \mathrm{pMATM} 2}^{\mathrm{th}}{ }^{a} \\
\left(\mathrm{~g} \mathrm{~mol}^{-1}\right)\end{array}$ & $\begin{array}{l}M_{\mathrm{n}, \mathrm{PMATM} 2}^{\mathrm{exp}} \\
\left(\mathrm{g} \mathrm{mol}^{-1}\right)\end{array}$ & $D_{\mathrm{M}}{ }^{b}$ & $\begin{array}{l}\text { MATM2 } \\
\text { conv. }(\%)^{c}\end{array}$ & $\begin{array}{l}M_{\mathrm{n}}^{\mathrm{th} d} \\
\left(\mathrm{~g} \mathrm{~mol}^{-1}\right)\end{array}$ & $\begin{array}{l}M_{\mathrm{n}}^{\exp b} \\
\left(\mathrm{~g} \mathrm{~mol}^{-1}\right)\end{array}$ & $D_{\mathrm{M}}^{b}$ & $\mathrm{~d} n / \mathrm{d} c^{b}$ & $\begin{array}{l}\text { MMA } \\
\text { conv. }^{c}(\%)\end{array}$ & \multicolumn{2}{|c|}{$\begin{array}{l}{[\mathrm{MATM} 2] /[\mathrm{MMA}]} \\
\text { molar ratio }\end{array}$} \\
\hline b10 & 5000 & 6800 & 1.12 & 96 & 18500 & 21000 & 1.04 & 0.079 & 90 & $10 / 90$ & $11 / 89$ \\
\hline b50 & 14200 & 15200 & 1.13 & 94 & 19700 & 20000 & 1.14 & 0.054 & 93 & $50 / 50$ & $52 / 48$ \\
\hline
\end{tabular}

${ }^{a}$ Calculated using eqn (1). ${ }^{b}$ Determined by TD-SEC. ${ }^{c}$ Determined by ${ }^{1} \mathrm{H}-\mathrm{NMR} .{ }^{d}$ Calculated using the equation: $M_{\mathrm{n}}^{\text {th }}=[\mathrm{MMA}] /[\mathrm{macro}-\mathrm{CTA}] \times M_{\mathrm{MMA}} \times$ conv. (MMA) $+M_{\mathrm{n}, \mathrm{PMATM} 2}^{\mathrm{exp}}$

Table 2 CPDB-mediated RAFT synthesis of p(MATM2-stat-MMA) statistical copolymers

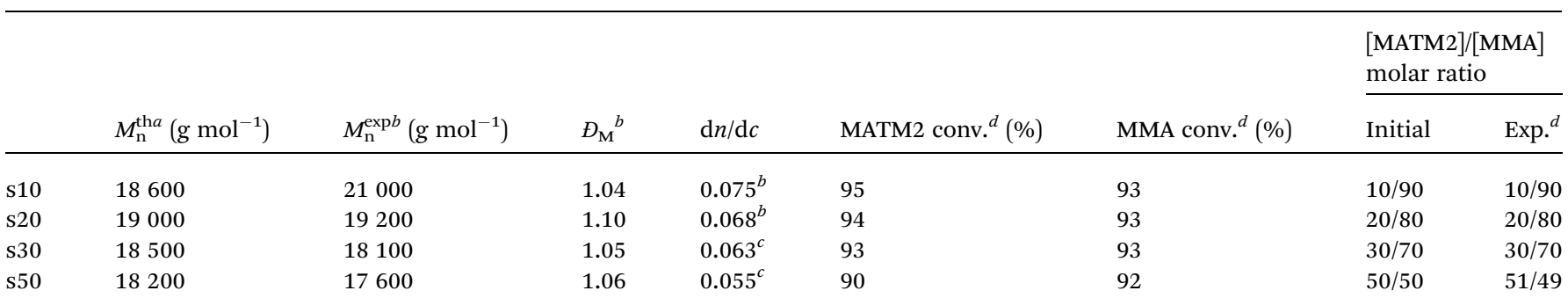

${ }^{a}$ Calculated using eqn (1) taking into account the total concentration of monomers and the equivalent molar mass. ${ }^{b}$ Determined by TD-SEC.

${ }^{c}$ Calculated from polymer composition (see ESI). ${ }^{d}$ Determined by ${ }^{1} \mathrm{H}-\mathrm{NMR}$. 
and $2.4 \mathrm{mmol} \mathrm{L}^{-1}$, respectively. The molar ratio of MATM2 was increased from 0.1 to 0.9 . The solutions were put in cylindrical tubes, degassed through bubbling with argon, sealed, and then placed simultaneously in an oil bath previously heated at $70{ }^{\circ} \mathrm{C}$, for $90 \mathrm{~min}$. The polymerization was stopped by rapid cooling in liquid nitrogen and by opening the polymerization tubes to air. The conversion and molar composition of the copolymers were determined by ${ }^{1} \mathrm{H}-\mathrm{NMR}$. Conversions of $\mathrm{ca}$. $10 \%$ were obtained. The equation of Mayo-Lewis and the least squares method were used to determine the reactivity ratios (see ESI $\dagger$ ).

\section{Results and discussion}

\section{Homopolymerization of MATM2}

To the best of our knowledge, there is no paper reporting the controlled radical polymerization of MATM2, and only one patent evoking its conventional radical copolymerization. ${ }^{\mathbf{1 0}}$ MATM2 homopolymerization was performed using two different CTAs, CPDB and CTA-0610 (Scheme 1) and without the use of CTA (conventional radical polymerization). CPDB and CTA-0610 were used as they are well-known to efficiently control the polymerization of (meth)acrylate monomers. ${ }^{11-13}$ The polymerization was carried out in xylene solution, with [MATM2] = $1.5 \mathrm{~mol} \mathrm{~L}^{-1}$ and $[\mathrm{CTA}] /[\mathrm{AIBN}]=5$, based on optimal conditions evidenced for TBDMSiMA. ${ }^{14}$ The targeted molar mass was $M_{\mathrm{n}}^{\mathrm{tg}}=$ $10000 \mathrm{~g} \mathrm{~mol}^{-1}$ at $100 \%$ conversion.

The RAFT homopolymerization of MATM2 was found to proceed with high monomer conversion (conv. $\geq 92 \%$ ) after 24 $\mathrm{h}$ in conventional and RAFT polymerization (Fig. S2 $\dagger$ ). An inhibition period, with virtually no polymerization, was observed for 35 min when CTA-0610 was used and $1 \mathrm{~h}$ with CPDB. This inhibition period, during the initial phase of the polymerization, is often reported in RAFT polymerization, and is generally associated (i) with a slow fragmentation rate of the initial intermediate macro-RAFT radical during the pre-equilibrium or (ii) a slow reinitiation rate of the leaving group of the initial RAFT agent. ${ }^{15-18}$ In the case of CPDB and CTA-0610, the leaving radical was ${ }^{\circ} \mathrm{C}\left(\mathrm{CH}_{3}\right)_{2} \mathrm{CN}$, the same radical as those resulting from the thermal degradation of AIBN, a conventional initiator, so the inhibition period was preferentially associated with a slow fragmentation rate of the intermediate radical. This phenomenon was accentuated for the dithiobenzoate CPDB, as the intermediate radicals are stabilized by the phenyl group through radical delocalization in the aromatic system. ${ }^{16}$
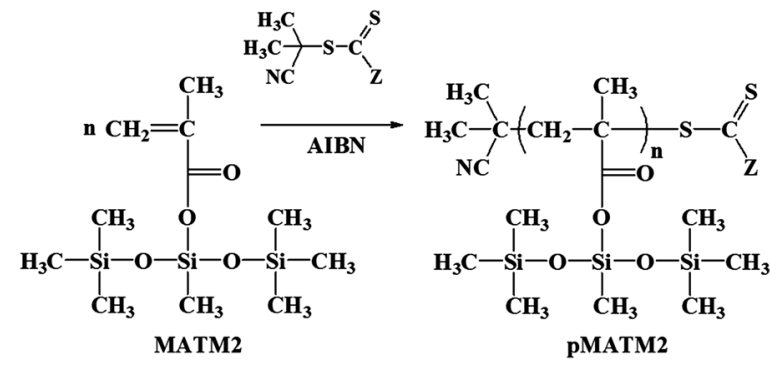

Scheme 1 Homopolymerization of MATM2 by the RAFT process.
The plot of $\ln \left([M]_{0} /[M]\right)$ versus the polymerization time is shown in Fig. 1. Contrary to conventional radical polymerization, in the presence of CPDB or CTA-0610, the kinetic plots were linear, indicating a first-order polymerization rate with respect to the monomer concentration and a constant concentration of the propagating radicals during the RAFT polymerization, revealing the absence of significant termination reactions. The RAFT homopolymerization of MATM2 proceeded at the same rate whatever the CTA used, but slower than in conventional radical polymerization due to the lower concentration of active species.

The number-average molar masses $\left(M_{\mathrm{n}}\right)$ of pMATM2 homopolymers were determined during the polymerization process by TD-SEC in THF, using the $\mathrm{d} n / \mathrm{d} c$ value of pMATM 2 determined on the homopolymer purified at the end of the reaction $\left(\mathrm{d} n / \mathrm{d} c(\right.$ pMATM2 $\left.)=0.044 \pm 0.001 \mathrm{~mL} \mathrm{~g}^{-1}\right)$. The evolution of $M_{\mathrm{n}}$ and $\emptyset_{\mathrm{M}}$ versus conversion is shown in Fig. 2.

In conventional polymerization, high $M_{\mathrm{n}}$ values of $\sim 110000$ $\mathrm{g} \mathrm{mol}^{-1}$ were obtained at the end of the polymerization together

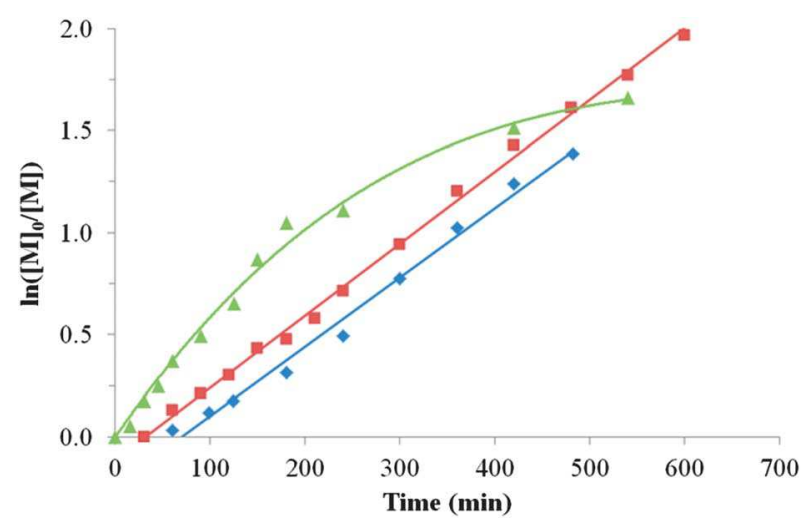

Fig. 1 Kinetic plots for the RAFT homopolymerization of MATM2, using $\triangle$ CPDB and $\square$ CTA-0610 as chain transfer agents, and $\triangle$ without CTA. Conditions: xylene, $70^{\circ} \mathrm{C}$, [MATM2] $=1.5 \mathrm{~mol} \mathrm{~L}^{-1}$, and [CTA]/ $[\mathrm{AIBN}]=5$

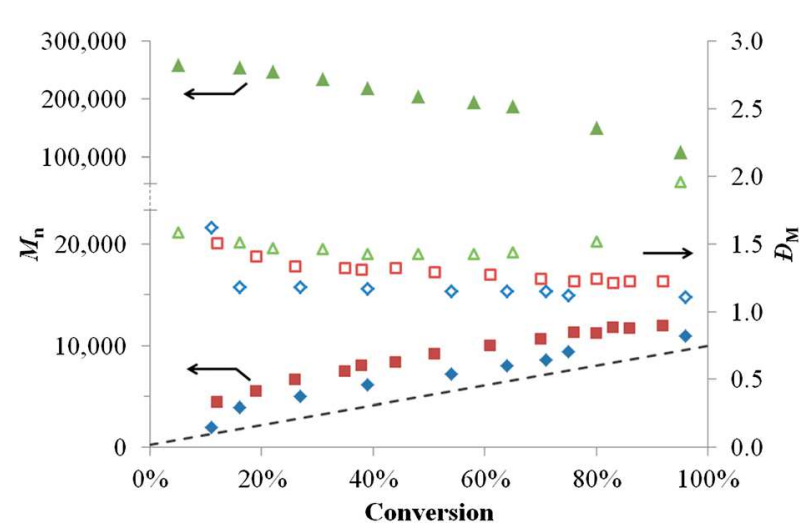

Fig. 2 Evolution of the molar mass $M_{n}(\Delta, \square, \Delta)$ and molar-mass dispersity $\emptyset_{M}(\diamond, \square, \triangle)$ versus MATM2 conversion, using $(\diamond, \diamond)$ CPDB and $(\square, \square)$ CTA-0610 as chain transfer agents, and $(\Delta, \triangle)$ without CTA. Conditions: xylene, $70{ }^{\circ} \mathrm{C}$, [MATM2] $=1.5 \mathrm{~mol} \mathrm{~L}^{-1},[\mathrm{CTA}] /[\mathrm{AIBN}]=5$, and $M_{n}^{\text {tg }}=10000 \mathrm{~g} \mathrm{~mol}^{-1}$. 
with relatively large molar-mass dispersity $\left(\bigoplus_{M}>2\right)$. During the polymerization, the trends are a decrease of the molar masses and an increase of $\emptyset_{\mathrm{M}}$, which are characteristic of conventional radical polymerization with no control of these polymerization features.

In the presence of CPDB or CTA-0610, the molar masses increased linearly with the MATM2 conversion indicating that no termination or transfer reactions occurred during the polymerization. Additionally, molar mass dispersities as low as 1.22 were obtained, revealing that all chains grew simultaneously. However, the experimentally observed molar masses were consistently higher than the theoretically predicted values, and a non-null molar mass can be extrapolated at zero conversion. This phenomenon has already been reported in other CPDBmediated RAFT polymerization techniques and was attributed to a low chain-transfer constant of the CTA in the polymerization. ${ }^{19,20}$ Notwithstanding, the final molar masses obtained with CPDB and CTA0610 were close to the targeted molar mass $\left(M_{\mathrm{n}}^{\mathrm{tg}}=10000 \mathrm{~g} \mathrm{~mol}^{-1}\right)$.

These results (first order kinetics, linear evolution of molar masses versus conversion, and low dispersity) proved that the RAFT homopolymerization of MATM2 was controlled by both CPDB and CTA0610. Considering its cost/molar mass ratio, CPDB was selected rather than CTA-0610 for the synthesis of copolymers.

\section{Synthesis of pMATM2-block-pMMA diblock copolymers}

pMATM2-block-pMMA copolymers were obtained by sequential RAFT polymerization (Scheme 2). MATM2 was first polymerized in the presence of CPDB and then MMA was added in the reaction media, leading to the extension of the chains of pMATM2, previously formed in situ, and further used as a macro-CTA.

A kinetic study was carried out during the synthesis of diblock copolymers containing $20 \mathrm{~mol} \%$ of MATM2 with $M_{\mathrm{n}}^{\mathrm{tg}}=$ $20000 \mathrm{~g} \mathrm{~mol}^{-1}$. The polymerization of MATM2 was performed in xylene, at $70^{\circ} \mathrm{C}$, using CPDB as a CTA, AIBN as an initiator, with $[\mathrm{CPDB}] /[\mathrm{AIBN}]=5 / 1$. The targeted molar mass for the first block pMATM2 was $8800 \mathrm{~g} \mathrm{~mol}^{-1}$. High MATM2 conversion was obtained after $24 \mathrm{~h}$, leading to a pMATM2-CTA with $M_{\mathrm{n}}=9200$ $\mathrm{g} \mathrm{mol}^{-1}$ and $\emptyset_{\mathrm{M}}=1.10$ (determined by TD-SEC, $\mathrm{d} n / \mathrm{d} c=0.044$ $\mathrm{mL} \mathrm{g}^{-1}$ ). The polymerization of MMA on PMATM2-CTA reached conversion of $90 \%$ after $48 \mathrm{~h}$ of reaction. The kinetic study by ${ }^{1} \mathrm{H}-\mathrm{NMR}$ and TD-SEC of the copolymerization of MMA shown in Fig. 3 revealed the linearity of both the evolution of $\ln \left([M]_{0} /[M]\right)$ versus time and the evolution of the molar mass versus conversion. Additionally, the dispersity remained low during the polymerization process $\left(\bigoplus_{M}<1.14\right)$. No induction period was observed during the polymerization of the second block. This is a common feature in RAFT polymerization using macro-CTAs since the main equilibrium of reversible transfer is directly established when the second monomer is added. The absence

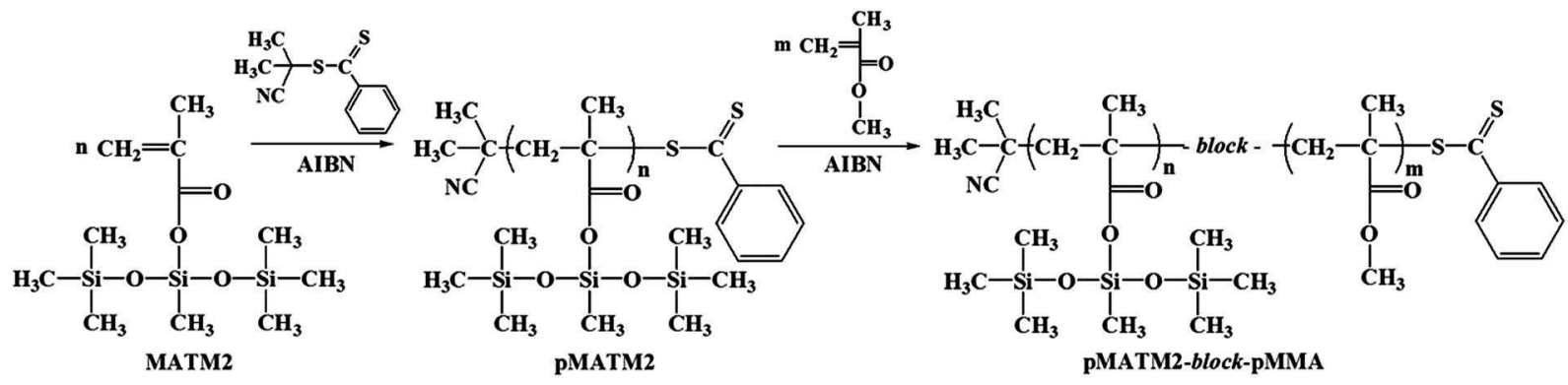

Scheme 2 Block copolymerization of MATM2 and MMA by the RAFT process.
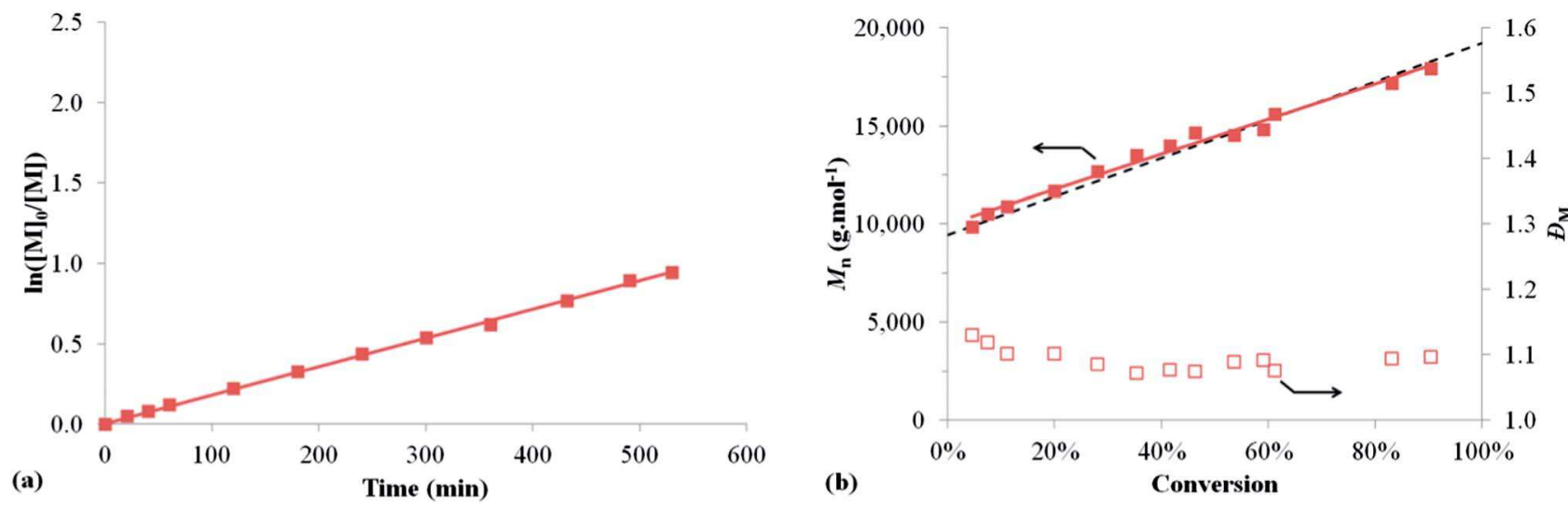

Fig. 3 (a) Evolution of $\ln \left([M]_{0} /[M]\right)$ versus time and (b) evolution of the molar mass $M_{n}$ and dispersity $\bigoplus_{M}$ versus conversion, during the polymerization of the second block of pMATM2-block-pMMA b20. $M_{n}$ and $\Phi_{M}$ are determined by TD-SEC, based on the estimated dn/dc values (see ESI†). 
of pre-equilibrium reactions enables to remove the inhibition period resulting from a low fragmentation constant rate of the intermediate radicals $\mathrm{RS}^{\cdot} \mathrm{R}$ and $\mathrm{PS}^{*} \mathrm{R}^{21}$

For all the range of pMATM2-block-pMMA copolymers, high MMA conversions were obtained after $48 \mathrm{~h}$ of reaction (conv. $\geq$ $90 \%$ ) (Table 1). Purified polymers were analyzed by TD-SEC to determine their $\mathrm{d} n / \mathrm{d} c$ and consequently their absolute molar masses. Polymers with molar masses close to $M_{\mathrm{n}}^{\text {tg }}$ were obtained with low molar-mass dispersity $\left(\bigoplus_{M}<1.2\right)$, demonstrating the control of the polymerization. An example of SEC chromatograms (RI signal) in Fig. 4 shows the peak related to the first pMATM2 block shifted toward lower elution times (higher molar masses), remaining narrow and monomodal for the corresponding diblock copolymer. This indicates the effective formation of the pMMA second block on the pMATM2 chains and the formation of diblock copolymers.

The molar composition of the copolymers was assessed via ${ }^{1} \mathrm{H}-\mathrm{NMR}$ spectroscopy from integrations of the three protons of the $-\mathrm{OCH}_{3}$ group in MMA (3.6 ppm) and the twenty-one protons of $-\mathrm{SiCH}_{3}(0.4$ to $-0.1 \mathrm{ppm})$ monomer units. The experimental compositions of the synthesized diblock copolymers were close to the theoretical values (Table 1). Consequently, well-defined pMATM2-block-pMMA copolymers were synthesized by CPDBmediated RAFT polymerization of MATM2 and MMA.

\section{Synthesis of p(MATM2-stat-MMA) statistical copolymers}

p(MATM2-stat-MMA) statistical copolymers were synthesized by simultaneous copolymerization of MATM2 and MMA, using

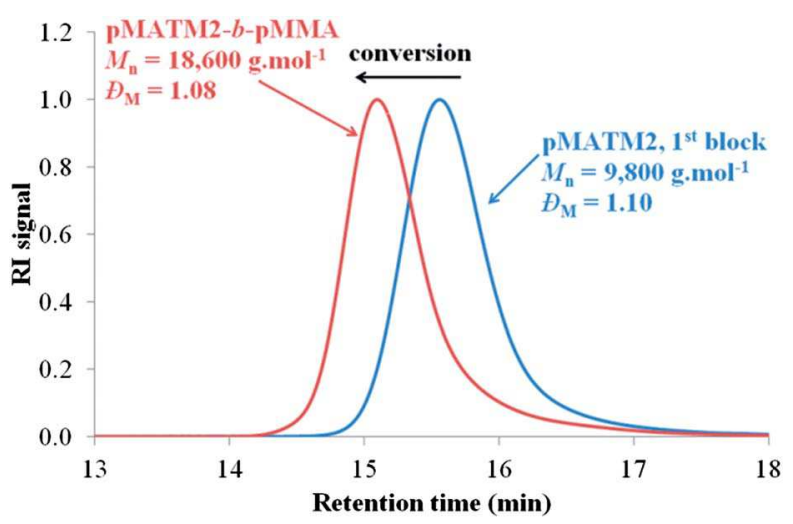

Fig. 4 SEC chromatograms of the pMATM2 first block and the final pMATM2-block-pMMA b20. CPDB-mediated RAFT polymerization, in xylene, at $70{ }^{\circ} \mathrm{C}\left(M_{n}\right.$ and $\emptyset_{M}$ values determined by TD-SEC).
CPDB as a CTA and AIBN as an initiator (Scheme 3). The targeted molar mass was $20000 \mathrm{~g} \mathrm{~mol}^{-1}$ and the MATM2 content varied between 10 and $50 \mathrm{~mol} \%$ of MATM2.

Relatively high monomer conversions were achieved for both monomers (conv. > 90\%) after $48 \mathrm{~h}$ (Table 2). Polymers were purified by precipitation in pentane (except for the copolymers s30 and s50 which did not precipitate in any common solvents). Purified polymers were analyzed by TD-SEC to determine their $\mathrm{d} n / \mathrm{d} c$ value and consequently their absolute molar masses. For non-purified copolymers, an estimation of their $\mathrm{d} n / \mathrm{d} c$ value was used (see ESI†). Polymers with molar masses close to the expected molar mass were obtained with low molar mass dispersity $\left(\bigoplus_{M} \leq 1.1\right)$.

\section{Reactivity ratios of MATM2 and MMA}

To determine the monomer reactivity ratios, a series of RAFT copolymerization reactions of MATM2 and MMA was also carried out to low conversion $(\sim 10 \%)$ with a wide range of monomer feed ratios (from 10 to $90 \mathrm{~mol} \%$ MATM2 in charge). Rather than using graphical methods such as Fineman-Ross ${ }^{22}$ or Kelen-Tudos, ${ }^{\mathbf{2 3 , 2 4}}$ the reactivity ratios were calculated from the final copolymer composition $F_{\text {MATM2 }}$ and the Mayo-Lewis equation, using the least square method (see ESI $\dagger$ ). The reactivity ratios calculated were $r_{\text {MATM2 }}=1.29$ and $r_{\mathrm{MMA}}=0.62$.

A $r_{\text {MATM2 }}$ value higher than unity reveals that the pMATM2 macroradical preferentially reacts with MATM2 monomers. Contrarily, an $r_{\text {MMA }}$ value lower than unity reveals that the pMMA $^{*}$ macroradical also preferentially reacts with MATM2 monomers showing clearly the inductive effect of the silicon atom leading to the MATM2 macroradical more stable. As $r_{\text {MATM2 }}>1$ and $r_{\text {MMA }}<1$, MATM2 monomers polymerized more rapidly than MMA, leading to a slight compositional heterogeneity in the synthesized statistical copolymers.

\section{Characterization}

Hydrolysis kinetics. Due to the structure of its monomer unit, pMATM2 was assumed to be hydrolyzable in seawater and alkaline media like more conventional poly(tri-alkylsilyl methacrylate)s used in self-polishing antifouling coating $\mathrm{s}^{3}$ (Scheme 4).

The hydrolysis kinetics of the pMATM2 homopolymer was investigated by in situ ${ }^{1} \mathrm{H}-\mathrm{NMR}$ spectroscopy and compared to other hydrolyzable homopolymers based on tri-isopropylsilyl (meth)acrylate (TiPSi(M)A), tert-butyldimethylsilyl (meth)acrylate
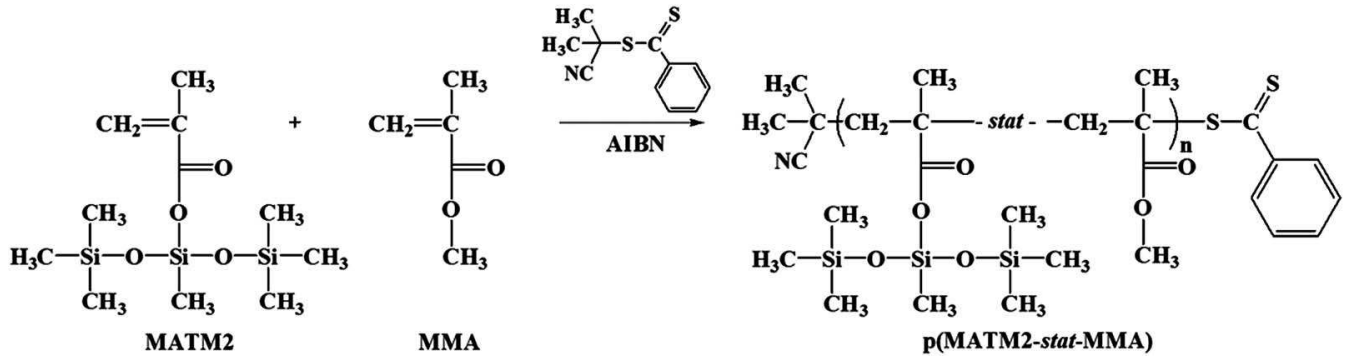

Scheme 3 Statistical copolymerization of MATM2 and MMA by the RAFT process. 


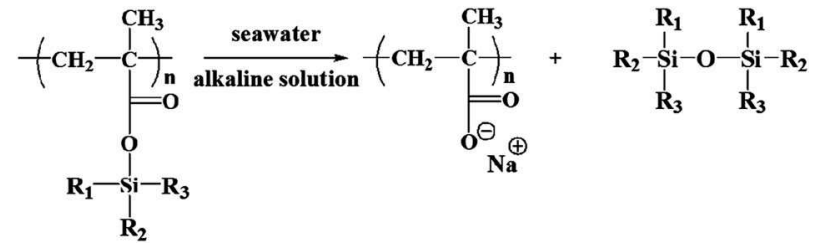

Scheme 4 Hydrolysis of tri-alkylsilyl methacrylic polymers in seawater and alkaline solution.

(TBDMSi(M)A), and tri-butylsilyl methacrylate (TBSiMA). All these hydrolyzable monomers were homopolymerized by CPDB-mediated RAFT polymerization with molar masses of $c a .10000$ $\mathrm{g} \mathrm{mol}^{-1}$ (data not shown).

Fig. 5 shows the evolution of the proportion of non-hydrolyzed monomer units for the six homopolymers evaluated. It reveals that PMATM2 can be hydrolyzed in alkaline media. In addition, a large range of hydrolysis kinetic rates were obtained depending on the structure of the hydrolyzable moiety. pTiPSiA and PTiPSiMA were almost non-hydrolyzed after 15 days at $\mathrm{pH}$ $=10$. Intermediate hydrolysis rates were observed for pTBSiMA and PTBDMSiMA, whereas PTBDMSiA and PMATM2 were more easily hydrolyzed. There was a noteworthy difference in the hydrolysis kinetics of pTBDMSiMA and pTBDMSiA, revealing the effect on the hydrolysis kinetics of the methyl group of the methacrylate compared to the acrylate. For pTiPSiMA and pTiPSiA, the difference between hydrolysis kinetics was not significant taking into account the precision of ${ }^{1} \mathrm{H}-\mathrm{NMR}$ analysis.

These hydrolysis kinetic studies demonstrated that pMATM2 homopolymers can be hydrolyzed like other poly(tri-alkylsilyl (meth)acrylate)s, therefore erosion properties like self-polishing coatings are expected for coatings based on MATM2 polymers. In addition, the effect of the alkyl group linked to the silicon atom was revealed in the case of poly(tri-alkylsilyl (meth)acrylate)s with a noteworthy steric hindrance of the tri-isopropyl moiety responsible for the low hydrolysis rates observed for pTiPSiMA and PTiPSiA.

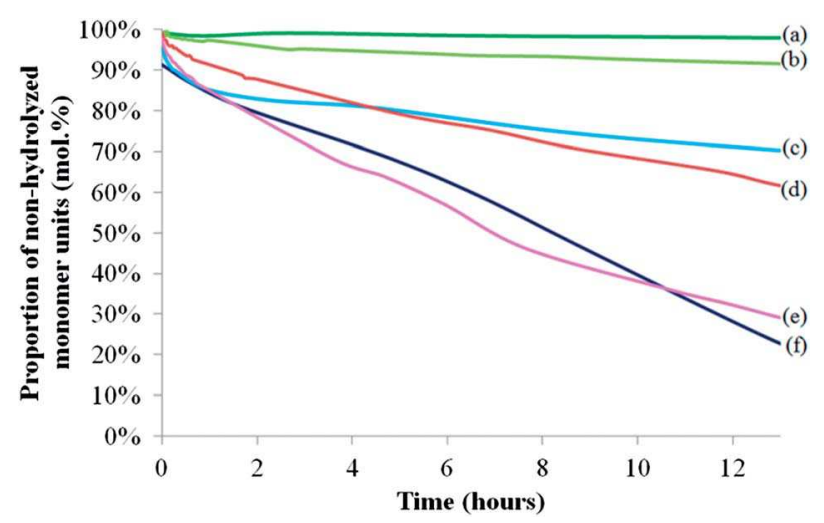

Fig. 5 Evolution of the proportion of non-hydrolyzed monomer units of several hydrolyzable homopolymer solutions in THF-d8, at $\mathrm{pH}=10$ : (a) pTiPSiA, (b) pTiPSiMA, (c) pTBDMSiMA, (d) pTBSiMA, (e) pMATM2, and (f) pTBDMSiA.
Thermal properties. The glass transition temperatures of the pMATM2 homopolymer and MATM2-containing statistical and diblock copolymers were investigated by DSC analysis. The results are shown in Table 3 and Fig. 6.

The DSC experiments were performed on purified polymer powders. Consequently, the statistical copolymers s30 and s50, which cannot be purified, were not analyzed by DSC. DSC analysis revealed that the $T_{\mathrm{g}}$ of the PMATM2 homopolymer was $5{ }^{\circ} \mathrm{C}$, while the $T_{\mathrm{g}}$ of pMMA is generally reported around $100^{\circ} \mathrm{C}$. The theoretical $T_{\mathrm{g}}$ of statistical polymers can be estimated using the Fox equation ${ }^{25}$ (eqn (4)):

$$
\frac{1}{T_{\mathrm{g}}^{\mathrm{th}, \mathrm{stat}}}=\frac{\omega_{1}}{T_{\mathrm{g}, 1}}+\frac{\omega_{2}}{T_{\mathrm{g}, 2}}
$$

where $\omega_{i}$ is the weight fraction of the monomer unit $i$ in the copolymer and $T_{\mathrm{g}, i}$ is the $T_{\mathrm{g}}$ of a homopolymer of the monomer $i$. The DSC analysis of statistical copolymers resulted in a unique glass transition at around 65 and $57^{\circ} \mathrm{C}$ for the copolymers s10 and s20, respectively. These $T_{\mathrm{g}}$ values are close to the theoretical values calculated using eqn (4). Meanwhile, two glass transitions at $7{ }^{\circ} \mathrm{C}$ and $73-84{ }^{\circ} \mathrm{C}$ can be detected for the pMATM2-block-pMMA diblock copolymers containing at least $30 \mathrm{~mol} \%$ of MATM2. The two $T_{\mathrm{g}} \mathrm{s}$ are close to the $T_{\mathrm{g}} \mathrm{s}$ of each block which is characteristic of diblock copolymers composed

Table 3 Glass transition temperature values of diblock and statistical copolymers of MATM2 and MMA, and their homopolymers

\begin{tabular}{llrl}
\hline Polymers & $T_{\mathrm{g}}^{\exp a}\left({ }^{\circ} \mathrm{C}\right)$ & & $T_{\mathrm{g}}^{\mathrm{th}, \mathrm{stat} b}\left({ }^{\circ} \mathrm{C}\right)$ \\
\hline pMATM2 & 5 & & \\
pMMA & & 100 & \\
S10 & 65 & & 70 \\
s20 & 57 & 93 & 52 \\
b10 & & 100 & 70 \\
b20 & & 84 & 52 \\
b30 & 7 & 73 & 39 \\
b50 & 7 &
\end{tabular}

${ }^{a}$ Measured by DSC. ${ }^{b}$ Calculated using eqn (4).

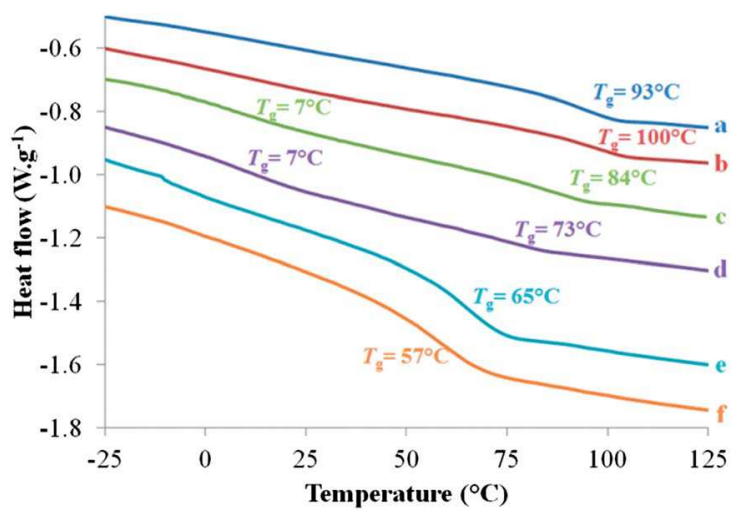

Fig. 6 DSC heating traces of pMATM2-block-pMMA copolymers (a) b10, (b) b20 (c) b30, (d) b50, and p(MATM2-stat-MMA) copolymers (e) s10 and (f) s20. 
of two immiscible blocks. This demonstrates that microphase separation occurred in the bulk sample of the pMATM2-blockpMMA diblock copolymers. For diblock copolymers b10 and b20, the molar fraction of MATM2 was too low to detect the $T_{\mathrm{g}}$ associated with the pMATM2 block. Only one $T_{\mathrm{g}}$ relative to the pMMA block was detectable around $93-100{ }^{\circ} \mathrm{C}$.

Contact angle analysis. Contact angle measurements were performed on coatings made from copolymer solutions in xylene, by the sessile drop technique by placing $1 \mu \mathrm{L}$ droplets of the test liquid. Static contact angles of deionized water, diiodomethane, and glycerol were measured at room temperature. The reported values are an average of five measurements on different regions of the same coating (Table 4). The polar and dispersive components of the surface energy were determined using the Owens Wendt method. ${ }^{9}$

Diblock copolymers exhibited higher contact angles than those measured for statistical copolymers, whatever the probe liquid used. They were hydrophobic with water contact angles closer to the values of standards of PDMS and FRC rather than the SPC standard. For diblock copolymers, the values of $\theta_{\mathrm{w}}$ and $\theta_{\text {gly }}$ were close to $100^{\circ}$ and little varied with the MATM 2 content while the values of $\theta_{\mathrm{CH}_{2} \mathrm{I}_{2}}$ increased when the MATM2 increased. For statistical copolymers, the values of $\theta_{\mathrm{w}}$ and $\theta_{\mathrm{CH}_{2} \mathrm{I}_{2}}$ increased with the MATM2 content but remained below those measured on diblock copolymer coatings. It is noteworthy that, in contrast to statistical copolymers, diblock copolymers exhibited a water contact angle of $c a \cdot 100^{\circ}$, even at low MATM2 content (10-20 mol\%), which is much higher than the value measured on the pMMA homopolymer $\left(\sim 80^{\circ}\right){ }^{\mathbf{2 6}}$

Surface energies were calculated from the values of $\theta_{\mathrm{w}}, \theta_{\text {gly }}$, and $\theta_{\mathrm{CH}_{2} \mathrm{I}_{2}}$, using the Owens-Wendt method. ${ }^{9}$ For all copolymers, the dispersive component $\gamma_{\mathrm{S}}^{\mathrm{d}}$ was the major contribution of the total surface energy $\gamma_{\mathrm{s}}$, and the contribution of the polar component $\gamma_{\mathrm{S}}^{\mathrm{p}}$ was minimal (Fig. 7). Diblock copolymers exhibited a much lower surface energy (15-25 $\mathrm{mJ} \mathrm{m}^{-2}$ ) than statistical copolymers $\left(28-38 \mathrm{~mJ} \mathrm{~m}^{-2}\right)$. Their surface energy was even lower than the surface energy of PDMS or FRC standards. For all the copolymers, the surface energy decreased when the content of MATM2 increased. Similar to contact

Table 4 Contact angles measured on coatings of pMATM2-blockpMMA and p(MATM2-stat-MMA) copolymers, and standards of PDMS, FRC and SPC

\begin{tabular}{lccc}
\hline Coatings & \multicolumn{1}{c}{$\theta_{\mathrm{w}}\left(^{\circ}\right)$} & $\left.\theta_{\mathrm{gly}}{ }^{\circ}\right)$ & $\left.\theta_{\mathrm{CH}_{2} \mathrm{I}_{2}}{ }^{\circ}\right)$ \\
\hline S10 & $71.1 \pm 3.4$ & $80.3 \pm 4.9$ & $41.1 \pm 1.9$ \\
S20 & $89.1 \pm 4.5$ & $81.4 \pm 10.8$ & $45.8 \pm 3.1$ \\
S30 & $93.8 \pm 0.8$ & $69.8 \pm 2.3$ & $53.5 \pm 1.3$ \\
S50 & $97.1 \pm 2.4$ & $93.5 \pm 2.8$ & $57.2 \pm 3.0$ \\
b10 & $102.2 \pm 3.1$ & $100.5 \pm \mathrm{v}$ & $61.2 \pm 4.5$ \\
b20 & $98.4 \pm 1.1$ & $99.1 \pm 1.6$ & $70.1 \pm 1.5$ \\
b30 & $101.2 \pm 1.4$ & $102.6 \pm 1.1$ & $75.2 \pm 0.8$ \\
b50 & $103.6 \pm 0.7$ & $106.2 \pm 0.8$ & $80.9 \pm 0.8$ \\
PDMS standard & $100^{a}$ & & \\
FRC standard & $105.5 \pm 1.0$ & $100.0 \pm 1.7$ & $51.4 \pm 1.4$ \\
SPC standard & $87.8 \pm 0.8$ & $82.2 \pm 0.7$ & $41.5 \pm 2.7$
\end{tabular}

${ }^{a}$ Ref. 27.

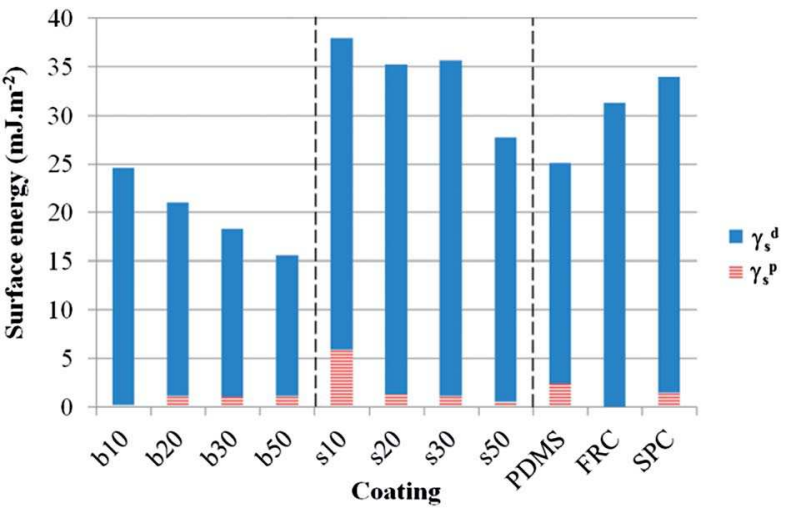

Fig. 7 Values of the surface energy $\gamma_{S}$ (as the sum of a dispersive $\gamma_{S}^{d}$ and a polar component $\gamma_{\mathrm{S}}^{\mathrm{p}}$ ) of pMATM2-block-pMMA diblock copolymer and $\mathrm{p}$ (MATM2-stat-MMA) statistical copolymer coatings, and standards of PDMS, FRC and SPC.

angles, a low proportion of MATM2 (10-20 mol\%) in diblock copolymers was sufficient to considerably decrease the surface energy of the copolymers compared to a pMMA homopolymer $\left(\gamma_{\mathrm{s}}=40 \mathrm{~mJ} \mathrm{~m}^{-2}\right),{ }^{26}$ which was not the case for statistical copolymers. For diblock copolymers, $\gamma_{\mathrm{S}}$ values lower than the surface energy of the pMATM2 homopolymer $\left(20 \mathrm{~mJ} \mathrm{~m}^{-2}\right)$ were even reached. This could be assigned to a specific surface organization of pMATM2 and PMMA phases at the surface of the coating.

\section{Conclusions}

This paper reports the first reversible addition-fragmentation chain transfer (RAFT) polymerization of bis(trimethylsiloxy) methylsilyl methacrylate (MATM2), an unconventional hydrolyzable monomer containing a siloxane group. Using 2-cyanoprop-2-yl dithiobenzoate (CPDB) or $S$-(2-cyanoprop-2-yl)- $S$ dodecyltrithiocarbonate (CTA-0610) as a chain transfer agent (CTA), the homopolymerization was shown to proceed with a first order kinetics and a linear evolution of molar mass versus conversion. Well-defined diblock and statistical copolymers with methyl methacrylate (MMA) were synthesized by CPDBmediated RAFT polymerization, with controlled molar masses and low dispersities $\left(\bigoplus_{\mathrm{M}}<1.15\right)$. DSC analysis revealed the influence of the copolymer architecture on their thermal properties and a microphase separation in pMATM2-block-pMMA diblock copolymers. In addition, diblock copolymers exhibited a much lower surface energy than statistical copolymers. This low surface energy combined with the hydrolysis properties of pMATM2 make the pMATM2-block-pMMA diblock copolymers appropriate candidates for use as binders in FRC/SPC hybrid antifouling coatings.

\section{Acknowledgements}

The authors acknowledge the Direction Générale de l'Armement (DGA) for financial support and Marcel Vos (PPG Coatings Europe B.V.) for fruitful exchanges. 


\section{Notes and references}

1 C. Bressy, A. Margaillan, F. Fay, I. Linossier, and K. Réhel, in Advances in Marine Antifouling Coatings and Technologies, ed. C. Hellio and D. M. Y. Yebra, Woodshead Publishing, Cambridge, UK, 2009, pp. 445-491.

2 M. N. Nguyen, C. Bressy and A. Margaillan, Polymer, 2009, 50, 3086-3094.

3 C. Bressy, M. N. NGuyen, B. Tanguy, V. G. Ngo and A. Margaillan, Polym. Degrad. Stab., 2010, 95, 1260-1268.

4 M. Lejars, A. Margaillan and C. Bressy, Chem. Rev., 2012, 112, 4347-4390.

5 M. Lejars, A. Margaillan and C. Bressy, Polym. Chem., 2013, 4, 3282-3292.

6 K. Matyjaszewski, in Controlled Radical Polymerization, ed. K. Matyjaszewski, American Chemical Society, Washington, DC, 1998, vol. 685, pp. 2-30.

7 Handbook of RAFT Polymerization, ed. C. Barner-Kowollik, 2008. 8 M. Destarac, Macromol. React. Eng., 2010, 4, 165-179.

9 D. K. Owens and R. C. Wendt, J. Appl. Polym. Sci., 1969, 13, 1741-1747.

10 M. Gillard and M. Plehiers, Hydrolysable binders and compositions. Patent EP1614722A1, 2006

11 G. Moad, E. Rizzardo and S. H. Thang, Aust. J. Chem., 2006, 59, 669-692.

12 G. Moad, E. Rizzardo and S. H. Thang, Aust. J. Chem., 2009, 62, 1402-1472.

13 G. Moad, E. Rizzardo and S. H. Thang, Aust. J. Chem., 2012, 65, 985 .
14 M. N. Nguyen, C. Bressy and A. Margaillan, J. Polym. Sci., Part A: Polym. Chem., 2005, 43, 5680-5689.

15 G. Moad, J. Chiefari, Y. K. Chong, J. Krstina, R. T. A. Mayadunne, A. Postma, E. Rizzardo and S. H. Thang, Polym. Int., 2000, 49, 993-1001.

16 C. Barner-Kowollik, M. Buback, B. Charleux, M. L. Coote, M. Drache, T. Fukuda, A. Goto, B. Klumperman, A. B. Lowe, J. B. Mcleary, G. Moad, M. J. Monteiro, R. D. Sanderson, M. P. Tonge and P. Vana, J. Polym. Sci., Part A: Polym. Chem., 2006, 44, 5809-5831.

17 S. Perrier, C. Barner-Kowollik, J. F. Quinn, P. Vana and T. P. Davis, Macromolecules, 2002, 35, 8300-8306.

18 P. Vana, T. P. Davis and C. Barner-Kowollik, Macromol. Theory Simul., 2002, 11, 823-835.

19 A. H. E. Müller, R. Zhuang, D. Yan and G. Litvinenko, Macromolecules, 1995, 28, 4326-4333.

20 I. Uzulina, S. Kanagasabapathy and J. Claverie, Macromol. Symp., 2000, 150, 33-38.

21 K. Kubo, A. Goto, K. Sato, Y. Kwak and T. Fukuda, Polymer, 2005, 46, 9762-9768.

22 M. Fineman and S. D. Ross, J. Polym. Sci., 1950, 5, 259-262.

23 T. Kelen and F. Tüdős, J. Macromol. Sci., Part A: Pure Appl.Chem., 1975, 9, 1-27.

24 F. Tüdos, T. Kelen, T. Földes-berezsnich and B. Turcsányi, J. Macromol. Sci., Part A: Pure Appl.Chem., 1976, 10, 1513-1540.

25 T. G. Fox, Bull. Am. Phys. Soc., 1956, 1, 123.

26 S. Wu, J. Polym. Sci., Part C: Polym. Symp., 1971, 34, 19-30.

27 A. A. Al-Juhni and B.-M. Z. Newby, Prog. Org. Coat., 2006, 56, 135-145. 